\title{
Livros pequenos e grandes problemas: $O$ feudalismo e a expansão européia medieval em textos de iniciação
}

Victor Deodato da Silva

Departamento de História - FFLCH-USP

Por piores que sejam em termos gerais determinadas vicissitudes, elas normalmente não deixam de apresentar aspectos particulares positivos. Publicado quando a Revista de História se encontrava com a publicação suspensa, um pequeno volume sobre a expansão militar européia na Idade Média Central (1) dificilmente teria suscitado mais do que uma curta resenha. Já examinado em conjunção com outro escrito da mesma coleção e da lavra do mesmo e competente autor, lançado algum tempo depois; desta vez versando sobre o feudalismo (2), termo que de uma certa forma engloba o conjunto de transformações sócio-institucionais que forneceram suporte à Cruzadas, em particular se consideradas na acepção ampla adotada no caso, ele suscita interessantes questões de método e interpretação que não se suporia facilmente, face às suas dimensões.

Comentando as "Indicações para leitura" no final do mais antigo dos trabalhos em exame o autor caracteriza certos itens - com elogiável dose de honestidade e realismo - como obras "de concepção semelhante

(1) - FRANCO JR., Hilário. - As Cruzadas (Col. "Tudo é História", $\mathrm{n}^{\circ}$ 34). São Paulo, Brasiliense, 1981, 90 páginas "in-16".

(2) - FRANCO JR., Hilário. - O Feudalismo (Col. "Tudo é História", n 65). São Paulơ, Brasiliense, 1983, 105 páginas "inn-160". 
à nossa, porém mais elaboradas pois, apesar de serem ambas também dirigidas a um público não especialista, trata-se nesse caso do público europeu, cujo leitor médio é de formação histórica superior ao nosso" (Cruzadas, p. 86). Num paralelo que cremos ser mais familiar, poderiamos dizer que a Coleção "Tudo é História" se configura como uma espécie de “Que sais-je?” (ou "Saber Atual”, em sua edição brasileira) em miniatura, sendo que o seu item respectivo é, por sinal, evocado no mesmo passo de nossa citação.

Em outras palavras, trata-se de sínteses extremamente reduzidas da ordem um quinto, ou talvez mesmo menos, das de "Que sais-je?" e como tais colocando problemas consideráveis aos seus autores, no caso presente bastante bem resolvidos. Aliás, caso o editor conseguisse (infelizmente, parece que esse não é bem o caso) manter o nível dos volumes em questão para o conjunto da coleção, estaria prestando um meritório serviço à miserabilíssima cultura histórica nacional que, para desespero de seus cultores e seguindo docilmente $o$ padrão intelectual em voga entre nós, deixa transparecer mais facilmente sintomas de regressão do que de evolução. Ao menos em termos de nível cultural médio dos interessados, embora oferecendo, cumpre admití-lo, como compensação não negligenciável uma ampliação quantitativa do mercado consumidor graças à proliferação dos cursos superiores de História no território nacional, a tornar economicamente viáveis iniciativas como as da coleção em causa.

Dentro, em suma, da proposta da coleção - uma síntese bem sucinta dos dados dísponíveis em relação a um tema histórico central — estamos diante de espécimens dignos de respeito pela segurança de seu conteúdo informativo, atualidade de sua bibliografia de apoio e clareza de exposição, propriedades aliás características do conjunto da produção de seu autor. Sob um prisma mais conjectural, estamos convictos de que essas virtudes encontrariam condições mais propícias para se destacarem caso o espaço que lhes foi oferecido fosse menos acanhado e certos detalhes de editoração, pelos quais supomos que os autores não têm qualquer carga de responsabilidade, não se configurassem como tão deprimentemente impróprios, como é o caso das ilustrações, oscilando entre um arcaismo bem século XIX (ainda assim o aspecto que menos incongruente se revela com a seriedade do texto) e um humorismo fácil (desta vez francamente fora de propósito), em alguns casos imbricados com uma estética de estórias de quadrinhos. Seguramente atentatórias ao espírito científico, não nos parece que elas se justifiquem melhor didaticamente, ao veicular uma imagem severamente distorcida do visual medieval.

Já é tempo, porém, de deixar de lado essas exterioridades e passar ao exame do teor desses escritos, cujos conteúdos, como já ressaltamos, 
apresentam afinidades tão estreitas que eles acabam se configurando como complementares entre si, o que se constituiu, como também já foi dito, na razão primordial desta nossa opção pela sua abordagem conjunta.

Com efeito, para o autor feudalismo é um termo que praticamente se identifica com a sociedade europeu-ocidental entre os séculos X e XIII em suas manifestações sócio-econômicas, político-institucionais e culturais, sobretudo da Europa Ocidental entre os séculos X-XIII (reservamos para o fecho desta resenha nossas considerações sobre uma conceituação tão abrangente), enquanto as Cruzadas, por sua vez, se configuram como uma espécie de válvula de escape para os desequilíbrios e tensões dessa mesma sociedade, explicando-se a defasagem cronológica de um século a um século e meio por terem seus desajustes e disfunções tardado compreensivelmente algum tempo para se fazerem sentir.

Essa visão explica as frequentes coincidências de conteúdo e em particular passagens do mais antigo desses volumes chegam a se constituir em "trailers" de partes de outro, fenômeno que, obviamente, não deve ser visto como sintoma de carência de disponibilidade de dados informativos ou insuficiência de recursos interpretativos a conduzir à repetitividade, já que esta, quando se observa ,se constitui em consequiência lógica da linha de abordagem adotada, a qual, por sua vez, aumenta singularmente a responsabilidade do historiador, na medida em que exige o máximo de sua erudição, dada a extrema diversidade de aspectos focalizados, cada um deles pressupondo uma formação bem específica. Nessas condições, chega a ser de admirar que, tanto quanto nos tenha sido dado detectar (mas é preciso dizer que a sorte dos autores em tais casos é que dos resenhadores se pressupõe uma gama de competência semelhante!), os lapsos sejam tão poucos, tanto mais que eles são praticamente inevitáveis, mesmo quando há uma circunscrição temática muito mais estreita do que a dos casos em questão.

Enumeremo-los. Franco Jr. estabelece um vínculo entre o deslanche do "Drang nach Osten" (2. ${ }^{\text {a }}$ metade do século XI) e a Hansa Teutônica (Cruzadas, p. 20), quando esta liga somente começou a ganhar corpo dois séculos mais tarde, apenas se constituindo formalmente já em pleno século XIV. É lógico que muitas das cidades que a compunham já se destacavam na atividade comercial e que seus interesses na matéria podem ter contribuído para a expansão alemã pará o leste, mas a verdade é que, enquanto tal, a dita associação ainda não existia. Na mesma página, podemos ler que os eslavos "além de serem pagãos tinham um nome interpretado como uma predestinação a serem escravos...", o que sugere que, ao inverter os dados da questão, o autor aparentemente ignora 
a noção bem comprovada de que foi por essa época ou talvez um ou dois séculos antes que a palavra "servus" passou a dar lugar a "sclavus", derivada de eslavo, porque os indivíduos dessa origem já vinham então sendo sistematicamente escravizados, sendo que em algumas línguas a forma dos dois nomes é virtualmente a mesma (como em inglês: slav e slave, eslavo e escravo respectivamente). Menos inexata do que incompleta se configura a referência a Compostela e Jerusalem como os grandes centros de peregrinação (Cruzadas, p. 33), esquecendo Roma, que inclusive deu aos que se dedicaram a essa prática um dos seus designativos, romeiro e que, o quão grande pudesse ser o vulto de eventuais concorrentes, em nenhum período da Idade Média ou ulteriormente deixou de atrair em massa os penitentes.

Mais relevantes do que lapsos desse tipo, praticamente inevitáveis em trabalhos do gênero, são as simplificaçõ̂es e generalizações. Ainda que se deva ressaltar que, numa certa medida, também se configurem como dificilmente contornáveis num escrito de intenção didática, na caso presente elas parecem decorrer pelo menos em parte do empenho quase obsessivo em abarcar a totalidade - ou seja, tanto em seus aspectos estáticos ou estruturais, quanto nos dinâmicos ou fisiológicos uma realidade em si mesma provavelmente menos organizada e coerente do que possa pretender o espírito humano. Em outras palavras, ao propor que "também as sociedades passam" pelo "ciclo vital" constituído por "gestação, nascimento, crescimento, reprodução, morte" (Feudalismo, p. 62), Franco Jr. talvez esteja levando um pouco mais longe do que dita a prudência o simile entre as sociedades humanas e os organismos vivos, u’a metáfora certamente sugestiva e útil para transmitir uma visão de processo histórico mas que, no final das contas, parece-nos não passar de uma metáfora e como tal deve ser considerada.

Essa concepção leva 0 autor a remontar às vezes longe no tempo (à procura dos ancestrais?) e não desejaríamos nos deter muito na discussão de aspectos que extrapolem significativamente das balizas cronológicas propostas (séculos X a XIII), mas por exemplo, não podemos deixar de assinalar que parece-nos exagerada simplificação da problemática religiosa do fim da Antiguidade reduzíla a uma oposição entre Cristianismo e "paganismo clássico" (Feudalismo, p. 27), sendo que esta última expressão somente se configura como válida na medida em que a identifiquemos com os cultos cívicos ou oficiais, o que omite o caráter extremamente aberto da postura politeísta, com sua extrema regionalização de práticas e concepções religiosas, com os cultos domésticos e de iniciação (ou mistérios) contrastando fortemente com as cerimônias promovidas pelo Estado. Também o problema do colonato no mundo 
romano (Feudalismo, p. 12) antecede de muito à época das dificuldades de obtenção de escravos e transcende sensivelmente à simples regressão no status jurídico do trabalhador livre, fenômeno esse que, consubstanciado nas leis impondo a hereditariedade de funções aos agricultores, esteve por sua vez mais ligado à evasão da mão-de-obra rural decorrente do flagelo das requisiçóes, do que às perturbações do comércio propriamente ditas e à decorrente queda na disponibilidade de escravos. Em relação a estas, é-nos difícil aceitar a afirmação peremptória de que "o setor mercantil" era o mais importante da Antiguidade (Cruzadas, p. 11), lugar comum generalizante merecedor de reparos já que mascara a enorme heterogeneidade econômica do Império Romano, com o ocidente - ressalvadas algumas áreas, sobretudo as de intensa colonização grega (p. ex. o sul da Itália e Sicília ou sul da Gália) - oferecendo, em forte contraste com o leste, um panorama de urbanização bastante artificial e dependente dos estímulos do poder central. Essa política, com efeito, não pôdo ser mantida duradouramente e a tendência à ruralização observada já a partir do século II nada mais representou do que um retorno à sua vocação profunda, disfarçada por algum tempo pelo fluxo de maciços recursos desviados do oriente, e pouco propícia à sustentação de setores secundários e terciários pujantes, a qual somente veio a se tornar efetivamente viável lá pelo terceiro século de nosso milênio, em circunstâncias que ora não vem ao caso esmiuçar.

Mas os maiores problemas - e são eles os que mais importam no momento - se referem ao período específico e mais particularmente à aplicação ao conjunto do espaço geográfico ocidental da etiqueta de "feudalismo". Eles começam com os mecanismos de relacionamento que estão na origem desse termo, ou seja, o contrato vassálico com o feudo como referencial, visto que, bem caracterizados na França, Catalunha, Inglaterra (mas nesta já com entorses, pois, à semelhança da Normandia, a monarquia desfrutava do monopólio das homenagens preferenciais, lige ou ligium), estados latinos orientais, Itália angevina e mais alguns outros bolsões bem esparsos, alhures eles conheciam pouca penetração. Como consequência, nessas áreas estranhas às práticas em questão, quando incidia, o vocabulário técnico que as regulamentava, na medida em que era adotado, estava sujeito a fortes alterações de significado (na Península Ibérica, por exemplo, o termo vassalidado designava relações tipicamente de clientela, via de regra não entrando em jogo o feudo).

Se em relação ao feudo e à vassalidado - que se constituem, na terminologia do autor e da qual não dissentimos, nos pontos de referência das relações horizontais - está mal caracterizada a generalidade de sua incidência pelo espaço geográfico em causa, a situação não é muito 
diversa no que concerne aos elementos fundamentais do relacionamento vertical, a senhoria e a servidão. Embora a detenção de grandes extensões de terra por um único personagem fosse um fenômeno bastante difundido, só na França e demais áreas por ela influenciadas instituicionalmente (basicamente coincidentes com a enumeração constante do parágrafo anterior), é que essa posse se condicionava ao compromisso de prestação de serviços próprios do contrato feudal. Como contra-partida e se constituindo em dado muito importante, os alódios, ou seja, pequenas e médias propriedades, se revelavam alhures bastante numerosos, não raro totalizando superfícies comparáveis ou mesmo superando às cobertas pelas grandes unidades agrárias (fossem elas senhoriais de tipo feudal, propriedades ou outras modalidades de posse). Da mesma forma, embora por toda parte as fórmulas de exploração dessas unidades (ou seja, nas quais a compensação dos serviços consistia na concessão de um lote para sustento dos que os prestavam) apresentassem traços básicos comuns, nem por isso se pautavam elas pelos mecanismos de dependência tão típicos, em sua regulamentação minuniciosa de serviços e taxas, do regime senhorial francês.

Mas mesmo em relação à França e às regiões por ela influenciadas institucionalmente os particularismos eram tão acentuados que um denominador comum fica muito difícil de ser apurado. O direito de bannum, tão importante para caracterizar a atomização das prerrogativas de governo e naturalmente evocado com destaque por Franco Jr. (Feudalismo, p. 51) era ignorado nas áreas que seguiam o costume normando, adaptado a um feudalismo "centralizado" e nas quais também a servidão não era praticada, o que nelas empresta - não obstante todas as afinidades que possam ser detectadas com o restante do território francês, a terra por excelência da "sociedade feudal" - uma coloração especial às relações a esta peculiares, tanto horizontal quanto verticalmente.

Nessas áreas - e mais o conjunto do oeste francês - observa-se uma outra tendência que o autor generaliza para todo o espaço geográfico ocidental, a saber, a obediência ao princípio de sucessão por primogenitura, importante em particular para explicar a expansão "feudal" (ou "Cruzadas" em suas várias frentes e acepções), na medida em que estimulava os filhos mais jovens a tentar a fortuna alhures. Incorre-se de novo então simplificação exagerada, pois tratava-se de um campo em que os mais mais imaginosos arranjos e as mąs variadas soluções eram adotados, não se verificando portanto a indivisibilidade mais ou menos automática do feudo por ele alegada, norma que somente se aplicava invariavelmente às honras (ou, mais simplificadamente, os títulos tais como conde, barão, etc.) e aos feudos que eventualmente as corporificassem, ou seja, aqueles 
que compreendessem os locais que forneciam a denominação aos títulos correspondentes, bem como os castelos que lhes serviam de sede e outras instalações oficiais.

Raros são, portanto, os lapsos mas em contrapartida consideráveis (ou ao menos assim nos parece) as distorções de enfoque que dão o que pensar. Vê-se que os dois livrinhos suscitam problemas interessantes, embora o leitor talvez estranhe que nos detenhamos tão longamente sobre trabalhos de iniciação obviamente despretenciosos e aos quais, em decorrência, é provável que o próprio autor, compreensivelmente, não atribua excessiva importância. Nesse caso, redarguiríamos que a relevância está nas próprias questões e que elas, no fundo dizem antes respeito às tendências interpretativas recentes da historiografia francesa, a chamada "nouvelle Histoire", que refletem claramente, do que às próprias obras ora em exame, as quais, como já o ressaltamos, são exemplares dentro dos propósitos que as animam. Explicitando melhor, a propensão generalizante e simplificadora - poderíamos mesmo dizer reducionista - nelas detectada decorre de uma adesão talvez um tanto ou quanto excessivamente decidida às concepções estruturalistas.

Este não é o momento de esmiuçarmos as origens complexas dessa corrente de pensamento, aliás bastante compósita em sua constituição e que estravasa notavelmente não apenas do terreno historiográfico, mas do próprio âmbito das ciências humanas. Acentuemos, porém, que em relação à História, disciplina por excelência das transformações, ela sempre se constituiu num problema, já que o próprio vocábulo "estrutura" transmite a noção do duradouro. Mas não é só. O termo parece também associado irremediavelmente à imagem de combinação complexa e integrada, consubstanciada no conceito de modelo - a um tal ponto que, conforme formulação célebre de Levy-Strauss, substituindo-se neste último um componente, fica todo o conjunto comprometido em sua coerência - o que gera problemas tanto de estabelecimento de limites de abrangência, quanto da atribuição de peso relativo entre as partes constituintes.

Neste passo coloca-se uma dificuldade, que poderíamos qualificar de epistemológica e que se delineia como de difícil superação. O estruturalismo, acabamos de dizê-lo, está comprometido com a noção de modelo, o qual, por sua vez, embora constituído a partir de alguns componentes ou propriedades do objeto a que se refere, de uma certa forma o antecede, constituindo-se, em escala consideıável, numa espécie de construção mental artificial. Nessas condições, é lícito sustentar que quanto mais abrangente um dado modelo se configurar em relação ao objeto, tanto maior será a multiplicação das variáveis a serem manipuladas e 
mais problemática a sua viabilidade. Sob pena de tornarmo-nos repetitivos (3), enfatizamos mais uma vez o nosso ceticismo quanto à factibilidade dos macro-modelos sociais ou históricos, os quais - ou, mais exatamente, um dos quais - nos parecem estar subjacentes nos trabalhos em exame.

Tentemos situar um pouco mais concretamente a questão.

Organização social rigidamente diferenciadora de dependentes e senhores (bem ilustrada pela economia dominial) e marcada por uma hierarquia complexa no seio deste último grupo (que tinha nas práticas feudo-vassálicas a sua mais característica manifestação); uma economia fundada no setor primário (agricultura, pastoreio e extrações), em função do qual se articulavam os outros, e isso de uma forma tão acentuada que o setor secundário ("industrial" ou mais realisticamente artesanal) tendia a se confundir com o terciário (serviços), grande apego aos valores religiosos, com um clero numeroso e influente sustentando uma propensão doutrinária conservadora, identificando a ordem vigente com a vontade divina e encarando as propostas renovadoras como tentações demoníacas; incipiência das instituições públicas, com a ação do Estado solapada tanto pelas usurpações privadas quanto pela força das disposições consuetudinárias; um modesto mas ininterrupto crescimento demográfico, a condicionar tanto uma renovação interna, quanto uma expansão, inclusive militar, externa.

Embora outros pudessem ser evocados, esses traços gerais são suficientes para dar corpo a um modelo e o autor certamente não foi o primeiro a delineá-lo, mas provavelmente é um dos que foi mais longe nesse sentido, ao aplicar a etiqueta de feudalismo ao conjunto das tendências que vimos de enumerar. Daí certas formulações, que soam um tanto estranhas, ao menos para nossos ouvidos, como "o Feudalismo era uma sociedade de ordens" (Feudalismo, p. 33: note-se a maiúscula) ou "a fraqueza populacional do Ocidente tinha começado lentamente a se modificar com o feudalismo" (Cruzadas, p. 15), inclusive porque investem o vocá-

(3) - Ver a respeito V. DEODATO DA SILVA. - "Dos macro-modelos sociais em História: Georges Duby e os modos de produção da Idade Média", Anais da II Reunião da Sociedade Brasileira de Pesquisa Histórica. São Paulo, 1983 , pp. $81-86$ e "O modo de produção e os problemas de periodização da Idade Média”, Relações Humanas (Revista do Instituto de Relações Sociais e Industriais). São Bernardo do Campo, $\mathrm{n}^{9} 5$, 1985, pp. 143-155. Esperamos publicar ainda em breve livro que se encontra em fase final de redaçấo, sob o título Mada de produça e trifuncionalidade social na Idade Média e na atualidade. 
bulo em questão de uma propriedade ativa, como se ele tivesse sido um sistema deliberadamente construído com todos os seus componentes conscientemente articulados e não se tratasse sobretudo de um conjunto de práticas só aos poucos consolidados e portanto, quanto mais se remonta às origens, fruto de tateamentos com pronunciados matizes de expediente e cuja plena sistematização nunca chegou a se completar. Mesmo porque pode-se dizer que, nascido de tendências centrífugas de uma fase conturbada da evolução da Cristandade, quando esta mais pôde enfim restaurar mecanismos centralizadores, estes só poderiam em última análise se desenvolver em detrimento dos particularismos que favorecem as soluções feudalizantes.

Não discordamos em princípio do postulado de que as "palavras, para o historiador, são sempre problemáticas" (Feudalismo, p. 7), mas esperamos que se perceba que está em jogo algo mais do que uma divergência terminológica, oue seja, que feudalismo no caso não passaria de uma etiqueta a designar o conjunto de tendências muito gerais detectáveis no ocidente europeu de então e em lugar da qual poderiam estar outras como sistema feudal, modo de produção feudal, civilização feudal, sociedade feudal (alternativas oferecidas pelo próprio autor, local citado). Inclusive porque em relação a estas permaneceria a mesma objeção: estar se-ia tomando o todo pela parte, pois se a idéia de uma civilização ocidental medieval encarada sob o prisma cultural ou mental se configura como relativamente defensável (ao menos em suas manifestações mais eruditas)', visto que a adoção generalizada do Cristianismo de linha romana fornecia um denominador omum poderoso, já nos parece infinitamente mais problemática a idéia de uma sociedade ocidental medieval, abarcando os aspectos sócio-econômicos ou político-institucionais, pois aí os particularismos e as variações regionais ganham um tal peso que incompatibilizam uma grande, se não a maior parte da área considerada com a combinação de vassalidade com dependências servil própria ao feudalismo na sua acepção mais ampla.

É evidente que existe o precedente de Marc Bloch, que já propunha a abordagem integrada e totalizante que não deixava de lado a bem dizer nenhum aspecto das relações humanas, mas, embora $L a$ société feódale refletisse, obra de síntese que era, a insuficiência de dados sobre alguns deles, uma das características mais marcantes do seu estudo reside precisamente numa ênfase quase obsessiva com os matizamentos. Uma vez transposto para o âmbito do estruturalismo, esse tratamento dificilmente deixaria de sofrer o reflexo das concepções marxistas - lembremos que Marx é um dos mais ilustres precursores dessa corrente - e Georges Duby propôs, em relação ao período de que tratam os dois 
livros, um modelo de modo de produção (4). Mas, ao fazê-lo, ele tomou duas providências cautelares: evitou maiores compromissos com o feudalismo em suas manifestações mais formais (tanto no concernente às relações horizontais quanto às verticais) e escudou-se numa atitude de modẻstia, alegando familiaridade sobretudo com o espaço geográfico francês, para eximir-se de estender ao conjunto do ocidente europeu a aplicação de sua proposta interpretativa. Menos prudente, Franco Jr. - cujo "approach" na matéria filia-se, ainda que sem servilismo, à mesma linha de abordagem - não hesitou em fazê-lo, incrementando a margem de vulnerabilidade que ela oferece.

Todavia, parece-nos pertinente afastar do espírito do leitor qualquer eventual suspeita de faccionismo partidário por parte de nosso autor. Em nenhum passo desses trabalhos ele denota estar extrapolando da missão intelectual de que se investiu, colocando-a a serviço de uma causa a ela extrínseca, por mais respeitável que seja. Ele não se enquadra certamente na categoria a que pertence um ex-aluno nosso - por sinal dentre os mais inteligentes e estudiosos que tivemos - que, no curso de uma discussão em classe, quando enunciávamos o princípio de que "enquanto ciência, a História justifica-se a si própria”, redarguia com um ar de desprezo mal disfarçado por um sorriso irônico: "mas professor, isso é idealismo kantiano!”. A nossa divergência com Franco Jr. é então epistemológica e não ideológica, porque continuamos convictos da inviabilidade dos macro-modelos sociais em virtude da inevitável multiplicação em seu interior de variáveis não raro incompatíveis entre si.

(4) - G. Duby. - Guerriers et paysans, VVIe.-XIIe. siècles. Prémier essor de l'économie europeéne. Paris, 1973. V. tb., do mesmo autor Les trois ordres ou l'imaginaire du féodalisme. Paris, 1978. 